\title{
A Review on The Critical Role of Occupational \& Environmental Medicine in The Hard Times of The Pandemic Covid-19
}

\author{
Sarli Fani ${ }^{1}$, Tsakmakis Epameinodas ${ }^{2}$, Dedes Dimitrios ${ }^{3}$ and Sarli Ioanna ${ }^{4}$ \\ ${ }^{1}$ Economist, Vice President at Primary Healthcare $3^{\text {rd }}$ Sector of Central Makedonia, General Hospital Papageorgiou, Greece. \\ ${ }^{2}$ Chemist, in Health and Environmental Factors, Regional Supervisor at Medical PharmaQuality, Greece.
}

${ }^{3}$ Health Administration, Greece.

${ }^{4}$ Geologist, MSc in Disasters Management, MSc in Health and Environmental Factors, Region of Attica, Directorate of Sports and Culture, Supervisor of Secretarial Department, Greece

*Corresponding author: Sarli Fani, Economist, Vice President at Primary Healthcare $3^{\text {rd }}$ Sector of Central Makedonia, General

Hospital Papageorgiou, Greece.

\begin{abstract}
Idea/Summary
The Pandemic Covid-19 that our society has been through since December 2019 has shed light on the critical role of Occupational and Environmental Medicine in the protection and promotion of Public Health taking into account the recent advances and progress achieved in the scientific world. The environment is totally associated with public health and the deterrence of diseases and infections can only be accomplished through healthy environments (WHO [1]). As per Johansson et al. [2], forecasting dynamics used in epidemiology research would enable scientists to battle epidemics of infectious diseases as seasonal epidemics of dengue as well as of other epidemics. The example of the Corona Virus COVID-19, which emerged in December 2019, is typical of the importance of prevention, proper education and timely response to health crises (WHO [3]). Appropriate actions to prevent the spread of the virus by properly washing hands, covering the cough and staying home for at least two weeks to prevent transmission of the disease are highly recommended to protect global population and thwart exposure to the virus.
\end{abstract}

Keywords: The Pandemic Covid-19; Occupational and Environmental Medicine; Public Health; Health Culture

\section{Scope/Awareness}

This review examines the challenges and scepticism that arise from the above concepts in order to foster and provide innovative solutions towards elimination, inhibition, eradication and prevention of harmful diseases and pandemics and the contribution of Occupational and Environmental Medicine in the protection and promotion of Public Health. Even though the concept of Occupational and Environmental Medicine is very critical for the protection and promotion of public health, worldwide as well as in the European territory, however, in Greece is still in a premature stage, underrated and underestimated and has not been given critical importance in the status and strategies of public health. Therefore, this review aims to raise awareness of the society and to draw attention to the critical concept of occupational and environmental medicine as a "Guardian" of Public Health.

\section{Methodology}

The methodology implemented is based on a review of relevant literature and latest research results collected. The outcomes arise from the analysis and examination of relevant incidents, perceptions and theories appeared in literature review and the 
results, questions and dilemmas that have not been answered, hence, the critical inquiries and new domains of science that need further research.

\section{Conclusions/Future Prospects}

Nowadays, health hazards and threats have been evolved, thus being more destructive and more threatening to public health, making them more devastating and more difficult to eliminate. The open access in scientific knowledge and the synergy of health scientists can result in better outcomes concerning the management in epidemics of infectious diseases. (Dong, Du, Gardner [4]). The Occupational and Environmental Medicine is found to be a multifaceted key factor in the protection and promotion of Public Health in a wide range spectrum of health strategies [5-13]. Concluding, all countries need to integrate health education and health strategies and espouse a holistic approach in health culture, so that public health will thrive to the benefit of the entire current population and future generations.

\section{References}

1. WHO (2006) Preventing Disease through Healthy Environments -Towards an estimate of the environmental burden of disease, Geneva.

2. Johansson MA, et al. (2019) "An open challenge to advance probabilistic forecasting for dengue epidemics", Proc Natl Acad Sci USA116 (48): 24268-24274.
3. WHO (2020) R\&D Blueprint: Coronavirus disease (COVID-19).

4. Dong E, Du H, Gardner L (2020) "An interactive web-based dashboard to track COVID-19 in real time". Lancet Infect Dis 20(5): 533-534.

5. Baumann A, O’Brien Pallas L, Armstrong Stassen M, Blythe J, Bourbonnais R, et al. (2001) Commitment and Care: The Benefits of a Healthy Workplace for Nurses, Their Patients and the System. Ottawa, Canada: Canadian Health Services Research Foundation.

6. Global Climate and Health Alliance (GCHA), a worldwide alliance of health Non-Governmental Organizations (NGOs), health professional organizations and health and environment alliances.

7. Global Health Policy Forum.

8. Intergovernmental Panel on Climate Change (IPCC ) (2019) Special Report on Climate Change, Desertification, Land Degradation, Sustainable Land Management, Food Security, and Greenhouse gas fluxes in Terrestrial Ecosystems.

9. Patra S (2018) "Public Health: Infectious Vs Chronic Diseases”. Journal of Biomedical Sci 7(4):15.

10. Soteriades ES, Falagas ME (2006) "A bibliometric analysis in the fields of preventive medicine, occupational and environmental medicine, epidemiology and public health". BMC Public Health 6(1): 301.

11. WHO (2016) Climate Change and Human Health.

12. WHO (2017) on behalf of the European Observatory on Health? Systems and Policies Publications, WHO Regional Office for Europe, Scherfigsvej 8, DK-2100 Copenhagen, Denmark Economou C, Kaitelidou D, Karanikolos M, Maresso A (2017) Greece: Health system review. Health Systems in Transition19(5): 1-192.

13. WHO (2018) Campbell-Lendrum D, "Climate Change, Health and the SDGs".

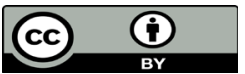

This work is licensed under Creative Commons Attribution 4.0 License

To Submit Your Article Click Here:

Submit Article

DOI: $10.32474 /$ RRHOAJ.2020.06.000227

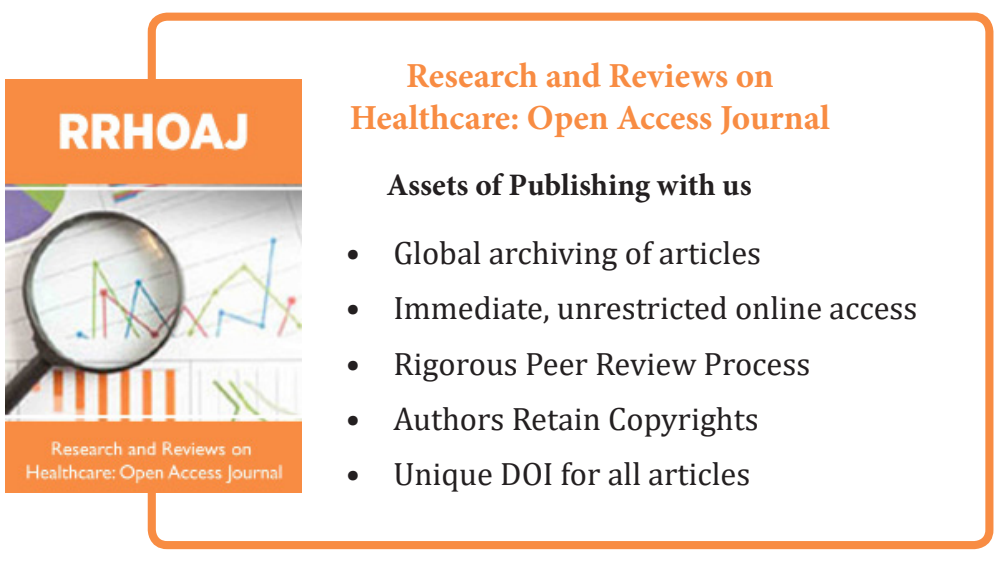

